\title{
Upper body injuries in Greek kayak flat-water athletes during a season period (2012-2013)
}

\author{
Thomas P. Papadas,' John A MacLean ${ }^{2,3}$ and Katy Stewart ${ }^{2,3}$ \\ 'MSc Physiotherapist, Olympiacos B.C., Greece \\ ${ }^{2}$ University of Glasgow, Scotland \\ ${ }^{3}$ Hampden Park Sports Health and Injury Clinic, Glasgow, Scotland
}

Correspondence: Thomas P. Papadas, 20 Thiras Street Salamina Attica, Greece 18900, Email tompapadas87@gmail.com

Received: September 7, 2018 | Published: November 30, 2018

Copyright@ 2018 Papadas et al. This is an open access article distributed under the terms of the Creative Commons Attribution License, which permits unrestricted use, distribution, and reproduction in any medium, provided the original author and source are credited.

\begin{abstract}
Aim

To provide epidemiological data on flat-water kayaking injuries of the upper body in Greece. Specifically, to assess the body part that sustains most injuries, the exact time period that injuries occur during a season, the type of musculoskeletal injury and the total injury rate using a descriptive study.

Methods

A retrospective injury surveillance took place during the Greek kayak flatwater 2013 championship from 12th to 14th July at "Schinias" Olympic Rowing and Canoeing Centre in Athens aiming to collect data of injury caused by sprint kayaking within a season period (dating from August 2012to July 2013). For this reason, a questionnaire, which was designed via the adaptation of previous retrospective questionnaires referring to different forms of kayaking, distributed to participants in order to gather information regarding paddlers' characteristics and the injury event. Descriptive analysis of the data was performed.
\end{abstract}

\section{Introduction}

Kayaking has many different competitive forms. Flat-water (sprint) kayaking is one of them and it is often considered to be a very hard sport activity included in the Olympic Games since the Berlin's 1936 Games. ${ }^{1}$ In 1991, the first National Championship of flat-water kayaking held in Greece according to the information obtained by the official website of the Greek Canoe - Kayak Federation. ${ }^{2}$

Even if plentiful literature exists on the sports that use predominantly the upper body (such as basketball, baseball, swimming and tennis), the general characteristics of injury related with sprint kayaking are mostly unknown due to the fact that the sport injury epidemiology research focused on it is too limited. ${ }^{3,4}$ Moreover, it is worth mentioning that there has not been any study investigating such an issue in Greece. Despite the few epidemiological data about injuries on flat-water kayaking, valuable information for this topic can be found in researches on various forms of kayaking. ${ }^{5-12}$

Indeed, a review of the literature related to kayaking found that only two studies focused on the characteristics of injury on flat-water kayaking. ${ }^{3,4}$ In particular, specific parts of the upper body prone to musculoskeletal injuries were reported in two studies. ${ }^{3,4}$ The shoulder was the most injured part of the upper body. Furthermore, the back and the wrist were also sites of musculoskeletal injury. ${ }^{3,4}$ Moreover,

\section{Results}

145 paddlers participated in our study. From these samples, 142 athletes responded to the questionnaires. The results are:56 paddlers $(39.4 \%)$ reported that they had had one or more injuries during the season. The shoulder $(21.1 \%)$ was the most injured body part followed by the wrist $(7.7 \%)$ and the lower back $(7.7 \%)$. Tendinitis $(41.9 \%)$ was the most frequently reported type of injury followed by strains $(25.8 \%)$ and sprains $(6.5 \%)$.According to the research, January $(6.3 \%)$ and February $(6.3 \%)$ were the months when most of the injuries had occurred followed by March $(4.2 \%)$. The total injury rate was 1.96 per 1000 hours of exposure.

\section{Conclusions}

This study provides valuable epidemiological data concerning the upper body injuries on flat-water kayaking. This could help future investigations on the risk factors and the injury prevention strategies.

Keywords: Kayak, flat-water kayaking, sport injuries, musculoskeletal injury

only one study focused on the type of injury. ${ }^{3}$ To put it in another way, this study focused specifically to the musculoskeletal injuries of the shoulder such as the rotator cuff tears, the biceps tendinitis and the shoulder bursitis without analyzing other regions of the upper body. ${ }^{3}$ None of the studies related to flat-water kayaking pointed out what the injury rate was and in which specific month the athletes suffered the most from musculoskeletal injuries. We should also take into account that there is not enough evidence to the location and the kind of injuries on sprint kayaking.

Articles published in medical literature referring to injuries related to various forms of kayaking, such as white water kayaking and outrigger canoe, argue that the upper body of the athlete undergoes a lot of injuries during paddling. ${ }^{5-12}$ In particular, most of the studies related to different forms of kayaking reported that the shoulder was the most prone site to musculoskeletal injuries. ${ }^{5-9,11}$ Moreover, other sites of musculoskeletal injury were the back, the wrist, the hands, the neck, the fingers and the elbows..$^{5-9,11,12}$ Regarding the type of musculoskeletal injuries, ligamentous sprains and strains were commonly reported. ${ }^{7-10}$

Also, other types of injury such as tendonitis and dislocation were stated in most of the studies. ${ }^{7-10}$ In addition, it was mentioned that the severity of the injuries related to kayaking were slight to minor. 
Moreover, it was mentioned that paddlers who participated in long distance events and both long and short distance events reported more injuries than those who only participated in short distance events. ${ }^{6,7}$ Finally, some of the studies supported that more injuries occurred during training than during competition. ${ }^{7-10}$

Regarding the need for more epidemiological data related to the injuries on flat-water (sprint) kayaking and the absence of such a study related to flat-water kayaking in Greece, the aim of this study was to investigate injuries, in particular musculoskeletal injuries of the upper body in Greek kayak flat-water athletes. Specifically, the aim was to highlight the upper body region which is at the highest risk of musculoskeletal injuries sustained during a season period (dating from August 2012 to July 2013) in Greek competitive kayak flat-water athletes and the exact time period when the majority of those injuries occur, taking into account that there have not been any retrospective studies investigating such an issue in Greece. In other words, the particular study tried to provide sufficient answers to the following research questions: which the site of the upper body that sustains most musculoskeletal injuries is, which the most common types of injury are, during which exact time period these occur and which the total injury rate is. The findings obtained from this study will not only help us recognize which part of the upper body is at risk of injury and when these most likely occur but it also provide valuable epidemiological data related to the characteristics of injuries on kayak flat-water (sprint). Hopefully, these data will assist other studies to identify risk factors and prevention methods.

\section{Methodology}

This research was a retrospective injury surveillance of Greek competitive kayak flat-water paddlers in which participants voluntarily completed a questionnaire addressing musculoskeletal injuries sustained during a season period (dating from August 2012 to July 2013). The questionnaire was composed in order to provide sufficient answers to the following research questions: a) which the site of the upper body that sustains most musculoskeletal injuries is, b) during which exact time period these occur c) which the most common types of injury are, and d) which the total injury rate is. The study received approval by the bioethics committee of the University of Glasgow.

\section{Subjects}

To be included in the relevant study, participants should be competitive male or female kayak flat-water (sprint) paddlers from Greece who took part in the Greek kayak flat-water 2013 championship (from $12^{\text {th }}$ to $14^{\text {th }}$ July ) and are registered as athletes of the Greek canoe-kayak federation. Also, participants should have taken part in training and competitions of their team during the season 2012-2013. The former will not be geographically limited since in the Greek championship (which is the last race of the season) contestants / participants are kayak clubs from different areas of Greece. Participation in the study should be voluntary. 250 paddlers took part in the Greek kayak flatwater 2013 championship according to the information obtained by the Greek Canoe - Kayak federation. Based on that, the size of the examined sample was estimated to be 140 via the methodology described by Watson $\mathrm{J}^{13}$ According to this power calculation, we finally chose randomly 145 athletes to complete the questionnaires. All study participants were first required to give their informed consent in order to take part in this survey. For participants younger than eighteen years of age the informed consent was obtained from their guardians.

\section{Survey Instruments}

For the purposes of the study, a questionnaire was designed aiming to collect data concerning the site of the upper body that sustains most musculoskeletal injuries, the exact time period these occur, the most common types of injury, and the total injury rate. These data of injury caused by sprint kayaking within a season period (dating August 2012 to July 2013) was gathered during the Greek national Canoe-Kayak championship which took place from 12th to 14th July at "Schinias" Olympic Rowing and Canoeing Centre, Athens. The questionnaire was an adaptation of previous retrospective questionnaires referring to different forms of kayaking published by Fiore and Houston ${ }^{8}$ on injuries in outrigger canoe paddlers and Haley and Nichols ${ }^{6}$ on injuries in white water kayaking.

The questionnaire consisted of two parts. The first part (Part A) sought to provide general information concerning paddlers' age, gender, years of paddling, paddling frequency (the average number of days that the paddler paddled per week, the minutes that the paddler paddled per training session), dominant hand, preferable distance of race (short distance, long distance, both short and long distance) and cases of injuries during the season. Injury was defined as: "any injury that prevents a player from taking a full part in all training activities typically planned for that day and match play for more than 24 hours from midnight at the end of the day the injury was sustained". This definition was adapted from a study by Kemp SP et al. ${ }^{14}$ which was considered a sensitive and valid injury type of definition. In addition, this helped us to make a comparison with other epidemiological studies carried out in other forms of kayaking which used the same definition for the injury. Further data were obtained in the second part (Part B) which contained specific questions addressing the injury event, such as the month in which the injury occurred, the activity in which the injury occurred (competition, training) the part of the body which was injured, the activity in which this injury happened (race or training), the provision of medical attention, the type of musculoskeletal injury (Dislocation, Fracture, Sprain, Tendinitis) and the period of time when the paddler was unable to participate in training or race (Less than one week, 1-2 weeks, 2 weeks to 1 month, more than one month, permanent Disability). Moreover, skin injuries of the upper body were not included in the type of injuries, as this study only dealt with musculoskeletal injuries.

\section{Data and Statistical Analysis}

To preserve confidentiality in the process of data collection, subjects were given the option of enclosure the questionnaire into an envelope. After the collection of questionnaires, these were stored in a folder and coded into Microsoft Excel software (Microsoft, Redmond, WA, USA) for analysis. Descriptive analysis of the data was performed by using IBM SPSS software (vs. 19) (IBM Corporation, 1 New Orchard Road Armonk, New York, United States). Qualitative variables are expressed by absolute frequencies and percentages. Quantitative variables are presented as mean \pm standard deviation. Descriptive results are also illustrated by pie-charts, bar-charts and tables.

\section{Result}

We randomly chose 145 athletes to participate in our research, as it is previously referred.From this sample, 142 athletes responded to the questionnaires. That means asatisfying completion percentage of $98 \%$. All athletes who returned the questionnaires met the inclusion criteria. The general characteristics of the study population are summarized in Table 1. 
Table I Athletes characteristics

\begin{tabular}{|c|c|}
\hline Parameter & Value \\
\hline Age (yrs) & $19 \pm 6$ \\
\hline Males(n; \% ) & $86 ; 60.6$ \\
\hline Females(n;\%) & $56 ; 39.4$ \\
\hline Years of paddling & $6.8 \pm 4.5$ \\
\hline \multicolumn{2}{|l|}{ Paddling distance } \\
\hline Short (n; \%) & $54 ; 38$ \\
\hline Long (n; \%) & $33 ; 23.2$ \\
\hline Both short and long (n; \%) & $55 ; 38.7$ \\
\hline \multicolumn{2}{|l|}{ Dominant arm } \\
\hline Right (n; \%) & $122 ; 86.5$ \\
\hline Left $(n ; \%)$ & $19 ; 13.5$ \\
\hline \multicolumn{2}{|l|}{ Average days of paddling per week } \\
\hline All paddlers $(n=\mid 42)$ & $4.9 \pm 1.4$ \\
\hline Short distance paddlers $(n=54)$ & $4.9 \pm 1.4$ \\
\hline Long distance paddlers $(n=33)$ & $5.0 \pm 1.4$ \\
\hline Sort and long distance paddlers $(n=55)$ & $4.8 \pm 1.5$ \\
\hline \multicolumn{2}{|l|}{ Average minutes of paddling per day } \\
\hline All paddlers $(n=\mid 42)$ & $91.1 \pm 32.9$ \\
\hline Short distance paddlers $(n=54)$ & $91.0 \pm 30.9$ \\
\hline Long distance paddlers $(n=33)$ & $92.2 \pm 33.3$ \\
\hline Sort and long distance paddlers $(n=55)$ & $90.5 \pm 35.1$ \\
\hline \multicolumn{2}{|l|}{ Average exposure (hours / year) } \\
\hline All paddlers $(n=\mid 42)$ & $371.4 \pm 196.0$ \\
\hline Short distance paddlers $(n=54)$ & $372.4 \pm 196.9$ \\
\hline Long distance paddlers $(n=33)$ & $379.2 \pm 165.2$ \\
\hline Sort and long distance paddlers $(n=55)$ & $365.7 \pm 214.8$ \\
\hline \multicolumn{2}{|l|}{ Number of injuries during the season } \\
\hline All paddlers $(n=\mid 42)$ & 69 \\
\hline Short distance paddlers $(n=54)$ & 21 \\
\hline Long distance paddlers $(n=33)$ & 9 \\
\hline Sort and long distance paddlers $(n=55)$ & 39 \\
\hline \multicolumn{2}{|c|}{ Injury incidence per year (per 1000 hrs of paddling) } \\
\hline All paddlers $(n=\mid 42)$ & $1.96 \pm 3.92$ \\
\hline Short distance paddlers $(n=54)$ & $1.51 \pm 3.26$ \\
\hline Long distance paddlers $(n=33)$ & $1.19 \pm 2.44$ \\
\hline Short and long distance paddlers $(n=55)$ & $2.88 \pm 5.00$ \\
\hline
\end{tabular}

Regarding the injuries, the $60.6 \%(\mathrm{n}=86)$ of the examined sample of the athletesdid not have injuries directly related to kayaking during this season, while the $39.4 \%(\mathrm{n}=56)$ had had one or more injuries (Figure 1).

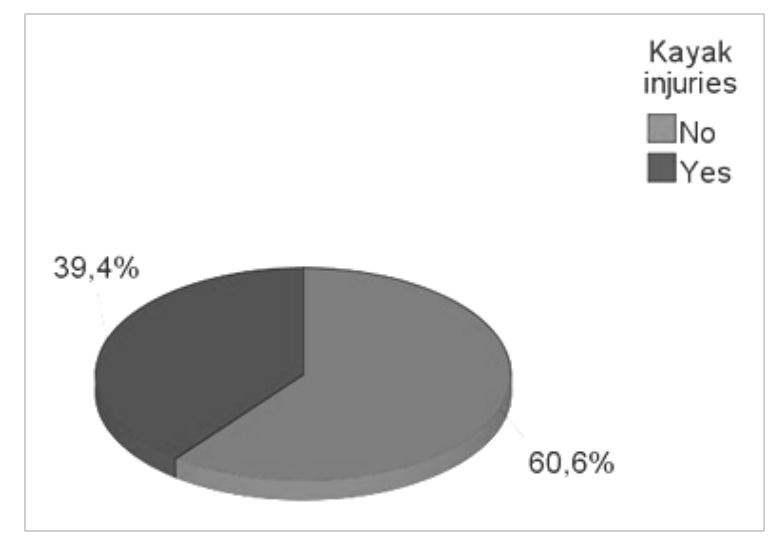

Figure I Kayak injuries.

In four cases $(7.1 \%)$ the injury occurred during competition, while in fifty two cases $(92.9 \%)$ the injury occurred during training (Figure 2 ).

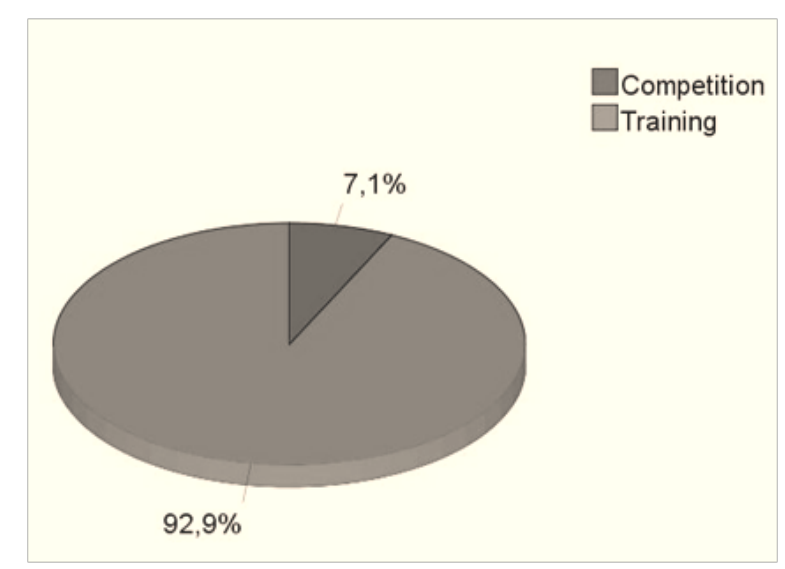

Figure 2 Percent of injuries occurred during competition and training activities.

Sixty nine injuries in total were reported from the injured paddlers. Participants in both long and short distance kayak flat-water races reported more injuries $(n=39)$, followed by the short distance paddlers who reported twenty one cases of injury and the long distance paddlers who reported nine cases of injury. The time period that the musculoskeletal injuries happened during the season is illustrated at Table 2 and Figure 3.

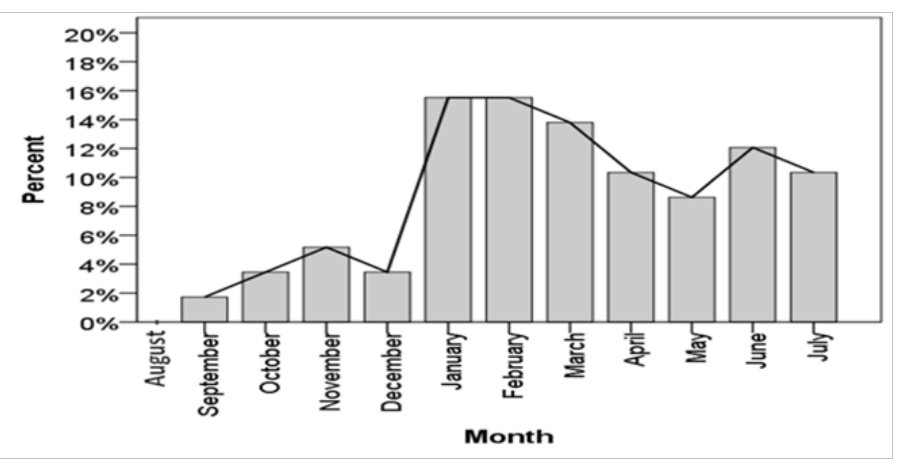

Figure 3 Percent of injuries during the year. 
Table 2 Distribution of lesions in the lower limb

\begin{tabular}{lll}
\hline Month & Frequency & Percent \\
\hline January & 9 & $6.3 \%$ \\
February & 9 & $6.3 \%$ \\
March & 8 & $5.6 \%$ \\
April & 6 & $4.2 \%$ \\
May & 5 & $3.5 \%$ \\
June & 7 & $4.9 \%$ \\
July & 6 & $4.2 \%$ \\
August & 0 & $0 \%$ \\
September & 1 & $0.7 \%$ \\
October & 2 & $1.4 \%$ \\
November & 3 & $2.1 \%$ \\
December & 2 & $1.4 \%$ \\
\hline
\end{tabular}

Table 3 Injuries occurred at various parts of the body

\begin{tabular}{lll}
\hline Body part injured & Frequency & Percent \\
\hline Head/Face & 0 & $0 \%$ \\
Neck & $\mathrm{I}$ & $0.7 \%$ \\
Ribs & 3 & $2.1 \%$ \\
Upper back & 3 & $2.1 \%$ \\
Lower back & $1 \mathrm{I}$ & $7.7 \%$ \\
Shoulder & 30 & $21.1 \%$ \\
Upper arm & 3 & $2.1 \%$ \\
Elbow & 2 & $1.4 \%$ \\
Forearm & 3 & $2.1 \%$ \\
Wrist & 11 & $7.7 \%$ \\
Hand & $\mathrm{I}$ & $0.7 \%$ \\
Fingers/Thumbs & $\mathrm{I}$ & $0.7 \%$ \\
\hline
\end{tabular}

The percentage of musculoskeletal injuries occurred at various parts of the upper body is reported at Table 3 . It is important to mention that the shoulder was the region of the upper body that sustains the most musculoskeletal injuries.

Moreover, the $41.5 \%$ of the injured athletes did not seek medical attention of his/her injury while the $58.5 \%$ did. The diagnosis for the injury for those who received medical attention is reported at Table 4.

Table 4 Diagnosis for injuries

\begin{tabular}{lll}
\hline Diagnosis & Frequency & Percent \\
\hline Dislocation & 0 & $0 \%$ \\
Strains & 8 & $25.8 \%$ \\
Sprains & 2 & $6.5 \%$ \\
Tendinitis & 13 & $41.9 \%$ \\
Other & 8 & $25.8 \%$ \\
\hline
\end{tabular}

Regarding the duration of musculoskeletal injuries, most of the paddlers $(49.1 \%, \mathrm{n}=27)$ reported that they were unable to paddle/ compete for less than one week. In addition, $20 \%(n=11)$ of the paddlers missed from one to two weeks of training because of their injury. The duration of injuries is illustrated at Table 5.

Table 5 Duration of Musculoskeletal Injury

\begin{tabular}{lll}
\hline & Frequency & Percent \\
\hline Less than one week & 27 & $49.1 \%$ \\
I-2 weeks & 11 & $20.0 \%$ \\
2 weeks to I month & 8 & $14.5 \%$ \\
More than one month & 8 & $14.5 \%$ \\
Permanent Disability & 1 & $1.8 \%$ \\
\hline
\end{tabular}

Finally, regarding the total injury rate for the kayak flat-water in Greece, it was $1.96 \pm 3.92$ per 1000 hours of paddling based on the total number of injuries and the average exposure on this activity over the 12 months retrospective period (Table 1). Also, the injury rate for short distance paddlers, long distance paddlers and for those who race in both short and long distances illustrated on Table 1.

\section{Discussion}

To our knowledge, this is the first epidemiological study to examine flat-water (sprint) kayak paddling- related to musculoskeletal injuries of the upper body in Greece. In other words, the present study provides unique and comprehensive information of the body part that sustains the most injuries, the exact time period that injuries occur during a season, the type of musculoskeletal injury and the total injury rate on flat-water paddlers in Greece. Although the number of paddlers $(n=142)$ who voluntarily participate in this research is relevantly small in comparison with other retrospective research ${ }^{7-9}$ it is similar to the target of participation that we calculated in advance of this research. As a result, the epidemiological data obtained from this research can be used with confidence.

$39.4 \%$ of the flat-water paddlers who participated in the present study reported one or more injuries during the season. This is a relevantly small percentage in comparison with other forms of kayaking. In particular, $62 \%$ and $42 \%$ of outrigger paddlers indentified by Haley et al. ${ }^{6}$ and Bell et al. ${ }^{7}$ respectively had at least one injury over the season. In addition, the majority $(92,9 \%)$ of injuries reported on this research occurred during training. This result is consistent with Krupnick et al. ${ }^{10}$ who also found that most of the injuries reported on white-water paddlers occurred during training. Moreover, most of the musculoskeletal injuries of the upper body reported in our study involved the shoulder $(21.1 \%)$ followed by the wrist $(7.7 \%)$ and the lower back (7.7\%). Abraham et al. ${ }^{5}$ also found that the shoulder $(35.6 \%)$ was the site mostly prone to musculoskeletal injuries when injuries of marathon paddlers were examined. The shoulder (40\%) was the most commonly reported site of injury in the study by Haley et al. ${ }^{6}$ They also reported that the back $(25.9 \%)$ and the wrist/hands $(9.9 \% \%)$ were sites prone to injury. Bell et al. ${ }^{7}$ reached the same conclusion since they had found that the shoulder (35\%) of outrigger canoe paddlers was the most common injury site followed by spine (27\%), elbow (11\%) and wrist (5\%). Our findings disagree with those reported by Carmont et al. ${ }^{3}$ who founded that the wrist $(21 \%)$ was the most injured part of the upper body on marathon kayaking followed by the shoulder (19\%) and back (14\%). 
Another important finding of this study is that most of the musculoskeletal injuries of the upper body occurred during the winter period and before the end of the season. In other words, most of the injuries were reported in January (6.3\%), February (6.3\%) and March $(5.6 \%)$ followed by June $(4.9 \%)$.This is the first study on kayaking which investigated the exact time period when most musculoskeletal injuries occurred. Attempting to explain these findings and because of the lack of relevant data, it could be possibly assumed that the low temperature during the winter period, the type of training and the poor recovery after training are some of the causes for the high percentages of injuries. Undoubtedly, this is a good starting point for future studies and for further investigation on this field.

Regarding the type of injury, Fiore et al. ${ }^{8}$ stated that tendinitis (25\%) was the most commonly reported type of musculoskeletal injury among whitewater kayaking paddlers followed by dislocation (17\%). Another study by Krupnick et al. ${ }^{10}$, focused on white-water paddlers who reported that the majority of musculoskeletal injuries were sprains (32\%) followed by tendonitis $(20 \%)$. Similarly, Bell et al. found that the greatest part of musculoskeletal injuries reported in their research was sprains /strains (62\%). Our study agrees with Fiore et al. since tendinitis $(41.9 \%)$ was the most frequent type of injury reported among flat-water paddlers. Moreover, other types of injury reported in our study were strains $(25.8 \%)$ and sprains (6.5\%).

The total injury rate in our study was 1.96 injuries per 1000 hours of exposure on flat-water kayaking. This is higher in comparison with the rate reported by Bell et Al. ${ }^{7}$ Specifically, Bell et al. ${ }^{7}$ reported that the overall injury rate for those who participate in outrigger canoe paddling was 1.82 per 1000 hours of exposure. Moreover, our study discovered that the injury rate of those who participated in both long and short distance races ( 2.88 per 1000 hours) was higher than the rate reported for short distance paddlers (1.51 per 1000 hours) and long distance paddlers (1.19 per 1000 hours) since paddlers who competed in both long and short distance reported more injuries $(n=39)$ than those who competed in short distance (21) and those who competed in long distance (39). In contrast to the findings of our study, the studies by Bell et al. ${ }^{7}$ and Haley et al. ${ }^{6}$ related to various forms of kayaking reported more injuries for long distance paddlers compared with short distance paddlers.

Most of the injuries reported in our study had short duration. In particular, $49.1 \%$ of the paddlers who reported injury lost less than one week of training/competition, while $20 \%$ of the paddlers missed from one to two weeks of training/competition. Bell et al. ${ }^{7}$ found that outrigger paddlers who reported an injury missed less than one week $(37 \%)$ or one to two weeks $(29 \%)$ of participation on their sport. Instead, a study by Halley et al. ${ }^{6}$ reported that only the minority of injuries lasted no more than one week $(10.8 \%)$ or one to two weeks $(24.8 \%)$, while the majority of injuries lasted two weeks to one month $(28.08 \%)$ or more than one month $(33.6 \%)$. Finally, the majority of the athletes reported that they sought medical attention for their injury $(58.5 \%)$. This contrasts with other studies related to various forms of kayaking which reported that most of the injured athletes did not received any medical care for their injury. ${ }^{6,7}$

Dealing with the limitations of our research, the retrospective nature was one of them. Particularly, our results may have been influenced by the existence of recall bias. We tried to control the recall bias via the minimization of the recall period to twelve months. Another limitation was that paddlers who dropped out of the sport because of an injury or did not attend the Greek kayak flat-water 2013 championship were not included in our research. Consequently, the total injury rate calculated in our research may has been influenced by the above factor. Moreover, participants in our research had to choose the type of their injury. This was also a limitation since the paddler is not a suitably qualified person in order to report accurately the type of his injury. Finally, our descriptive study was not designed to assess factors leading to specific injury events. The data presented in this study can help future studies in order to identify causes of injury and methods of injury prevention.

\section{Conclusion}

This is the first retrospective study addressing the site of the upper body that sustains most musculoskeletal injuries, the exact time period these occur, the most common types of injury and the total injury rate during a season period in competitive kayak flat-water paddlers in Greece. Only, 39.4\% of the participants reported that had one or more injuries which means that this sport is safer compared to other forms of kayaking in which higher rates were recorded. Furthermore, the total injury rate was relevantly small. In most of the cases the duration of the injury was short and the paddlers sought medical attention. Additionally, the shoulder was the part of the upper body that sustained most musculoskeletal injuries, while tendinitis was the most common type of injury. Moreover, most of the injuries occurred during January and February. Paddlers participated in both long and short distances and short distances reported more injuries in comparison with long distance paddlers. Hopefully, our data will assist further studies on flat-water kayaking with prospective nature and large sample size to identify risk factors and prevention methods. After that the participation on flat-water kayaking will be even safer.

\section{References}

1. Canoe Sprint. ICF - Planet Canoe. https://www.canoeicf.com/discipline/ canoe-sprint. Accessed November 28, 2018

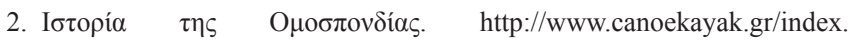
php?option $=$ com_content\&view $=$ article $\&$ id $=46 \&$ Itemid $=64$. Accessed November 28,2018

3. Carmont MR, Baruch MR, Burnett C, Cairns P, Harrison JK. 001 Injuries Sustained During Marathon Kayak Competition: The Devizes To Westminster Race. Br J Sports Med. 2004;38(5):650.

4. Edwards A. Injuries in kayaking. Sport Health. 1993;11:8-8.

5. Abraham D, Stepkovitch N. The Hawkesbury Canoe Classic: Musculoskeletal injury surveillance and risk factors associated with marathon paddling. Wilderness Environ Med. 2012;23(2):133-139.

6. Haley A, Nichols A. A survey of injuries and medical conditions affecting competitive adult outrigger canoe paddlers on Oahu. Hawaii Med J. 2009;68(7):162.

7. MMPhty RB, PGDipMPhysio Bp, Steve Tumilty PhD Mp. Sports injury profile of competitive Waka Ama (outrigger canoe) paddlers in New Zealand. N Z J Physiother. 2013;41(1):30.

8. Fiore DC, Houston JD. Injuries in whitewater kayaking. Br J Sports Med. 2001;35(4):235-241.

9. Schoen RG, Stano MJ. Year 2000 whitewater injury survey. Wilderness Environ Med. 2002;13(2):119-124.

10. Krupnick JE, Cox RD, Summers RL. Injuries sustained during competitive white-water paddling: a survey of athletes in the 1996 Olympic trials. Wilderness Environ Med. 1998;9(1):14-18. 
11. Kameyama O, Shibano K, Kawakita H, Ogawa R, Kumamoto M. Medical check of competitive canoeists. J Orthop Sci. 1999;4(4):243-249.

12. du Toit P, Sole G, Bowerbank P, Noakes TD. Incidence and causes of tenosynovitis of the wrist extensors in long distance paddle canoeists. $\mathrm{Br}$ J Sports Med. 1999;33(2):105-109.
13. Watson J. How to determine a sample size: Tipsheet\# 60. Univ Park PA Penn State Coop Ext. 2001.

14. Kemp SP, Hudson Z, Brooks JH, Fuller CW. The epidemiology of head injuries in English professional rugby union. Clin J Sport Med. 2008;18(3):227-234 